\title{
Nobody's perfect: can irregularities in pit structure influence vulnerability to cavitation?
}

\author{
Lenka Plavcová1 *, Steven Jansen ${ }^{1}$, Matthias Klepsch ${ }^{1}$ and Uwe G. Hacke \\ 1 Institute for Systematic Botany and Ecology, Ulm University, UIm, Germany \\ ${ }^{2}$ Department of Renewable Resources, University of Alberta, Edmonton, AB, Canada
}

\section{Edited by:}

Qiang Sun, University of

Wisconsin-Stevens Point, USA

\section{Reviewed by:}

Zhong-Nan Yang, Shanghai Normal

University, China

Hannetz Roschzttardtz, University of

Wisconsin-Madison, USA

*Correspondence:

Lenka Plavcová, Institute for

Systematic Botany and Ecology, UIm

University, Albert-Einstein-Allee 11,

D-89081 Ulm, Germany

e-mail: lenka.plavcova@uni-ulm.de
Recent studies have suggested that species-specific pit properties such as pit membrane thickness, pit membrane porosity, torus-to-aperture diameter ratio and pit chamber depth influence xylem vulnerability to cavitation. Despite the indisputable importance of using mean pit characteristics, considerable variability in pit structure within a single species or even within a single pit field should be acknowledged. According to the rare pit hypothesis, a single pit that is more air-permeable than many neighboring pits is sufficient to allow airseeding. Therefore, any irregularities or morphological abnormalities in pit structure allowing air-seeding should be associated with increased vulnerability to cavitation. Considering the currently proposed models of air-seeding, pit features such as rare, large pores in the pit membrane, torus extensions, and plasmodesmatal pores in a torus can represent potential glitches. These aberrations in pit structure could either result from inherent developmental flaws, or from damage caused to the pit membrane by chemical and physical agents. This suggests the existence of interesting feedbacks between abiotic and biotic stresses in xylem physiology.

Keywords: bordered pit, pit damage, pit membrane, pit ontogeny, structural irregularity, xylem vulnerability

\section{INTRODUCTION}

Adjacent xylem conduits in both gymnosperms and angiosperms are joined by common endwalls. In order to facilitate connectivity, the endwalls are permeable to water and dissolved substances, making the xylem network well suited for the long-distance transport of water, nutrients, and signaling molecules. A certain degree of xylem network compartmentalization is, however, desirable because it helps to confine the spread of air embolism and xylem-borne pathogens. The conflicting needs for the connectivity and isolation within the xylem network have been ingeniously solved by the evolution of endwall pitting.

Bordered pits in water-conducting xylem cells have a characteristic structure of two basic components - the pit membrane and the pit border. Pit membranes are uniformly thick and porous in most angiosperms, whereas two distinct regions - a thicker solid torus and a thinner highly porous margo - are characteristic for the pit membranes of gymnosperms. While pits shares common features in their overall structure, the finer-scale characteristics such as the pit size, pit membrane thickness, pit chamber depth, torus to aperture overlap vary substantially between different species (Jansen et al., 2009; Pittermann et al., 2010) as well as within the same species depending on growing conditions (Schoonmaker et al., 2010; Plavcová et al., 2011) or the position within a plant (Domec et al., 2008; Hacke and Jansen, 2009).

Looking for links between pit structure and embolism resistance has become very topical in the field of xylem hydraulics. Most studies so far have focused on the structure of a typical pit and assessed parameters such as mean pit membrane thickness, mean pit membrane porosity, or mean torus to aperture overlap. However, considerable variation in the structure of pits exists even within the same pit field (Figures 1A,B). Moreover, some pits exhibit remarkable structural aberrations, including particularly large pores independent of mean porosity in angiosperms (Figures 1A,C) and punctured or irregular tori in gymnosperms (Figures 1E-G). Arguably these pits, which represent the tails of, or even outliers in, the overall pit distribution, matter the most for the spread of embolism (Christman et al., 2009).Thus, the aim of this paper is (1) to highlight the existence of irregularities in pit structure that can have substantial influence on their permeability to air, and (2) to review possible mechanisms that can give rise to such irregularities.

\section{DEVELOPMENTAL IRREGULARITIES OF PIT MEMBRANES}

The ontogeny of pits is a complex process consisting of several steps. Pit development is initiated by the delineation of their outlines in the primary cell wall (Wardrop, 1954; Imamura and Harada, 1973), followed by the gradual deposition of secondary wall constituting pit borders (Chaffey et al., 1997) and the extensive hydrolysis and remodeling of pit membranes (Czaninski, 1972; Butterfield and Meylan, 1982; Kim et al., 2011).

In angiosperms, the selective hydrolysis of pit membranes is a critical step affecting their final porosity. While the chemical composition of pit membranes remains poorly characterized (Choat et al., 2008), it is generally assumed that most of the non-cellulosic components are removed before xylem conduits reach maturity (O'Brien and Thimann, 1967; Czaninski, 1972). Depending on the thickness of the pit membrane and the amount of amorphous material left after the hydrolysis, some pit membranes show pores embedded within the fibrillar meshwork, whereas other membranes appear non-porous when observed with scanning electron 

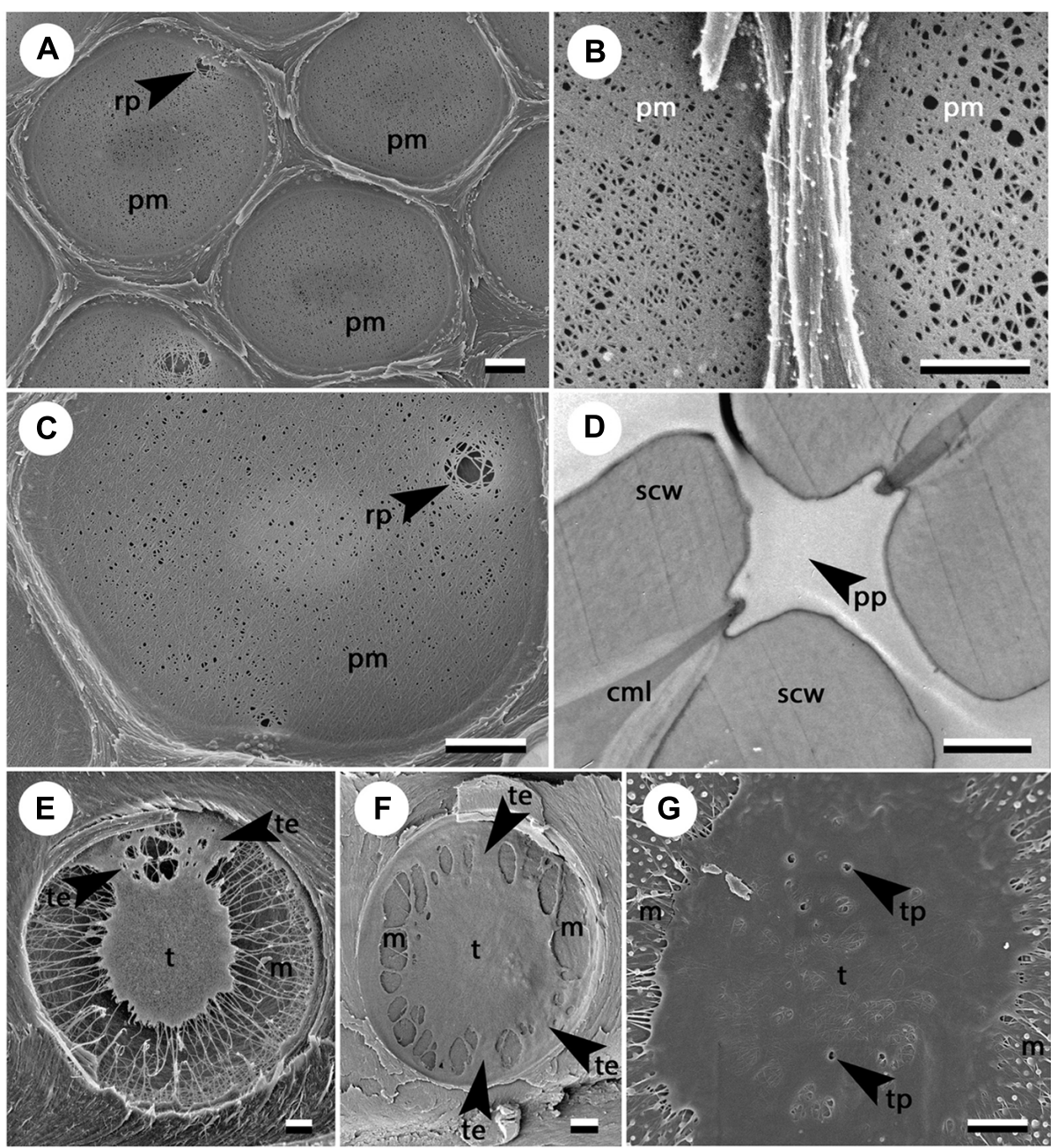

FIGURE 1 | Structural variability in adjacent pits (A, B) and examples of profound irregularities in pit structure (C-E). (A) Pit field in Acer negundo in which some pit membranes are homogenously porous while others show rare large pores (photo courtesy of Brendan Choat); (B) adjacent pits in hybrid poplar Populus trichocarpa $\times$ deltoides showing different average porosity; (C) rare large pore independent of the average porosity in Acer negundo (photo courtesy of B. Choat); (D) perforated pit in a non-conductive ITE in
Lycium andersonii: (E) sporadic torus extensions in Picea mariana (photo courtesy of Amanda Schoonmaker); (F) numerous torus extensions in Widdringtonia cederbergensis; (G) punctured torus in Sequoia sempervirens. Scale bars show $1 \mu \mathrm{m}$. Arrowheads indicate irregularities in the pit structure. $\mathrm{cml}$, compound middle lamella; m, margo; pm, pit membrane; pp, perforated pit; rp, rare large pore; scw, secondary cell wall; $t$, torus; te, torus extension; tp, torus perforation microscope (SEM; Jansen et al., 2009). In multi-cellular vessels, the primary cell wall of some endwalls is hydrolyzed completely, giving rise to perforation plates (Benayoun et al., 1981). Interestingly, transitional cases between scalariform perforation plates and pitted endwalls are sometimes found in ferns (Carlquist and Schneider, 1997, 2001) and basal groups of vessel-bearing angiosperms (Carlquist, 1992; Sperry et al., 2007). The pit membranes of vesselless angiosperms typically exhibit high porosity (Hacke et al., 2007). Furthermore, pits between imperforate tracheary elements (ITEs) provide an interesting comparison to intervessel pit membranes. In a recent study, Sano et al. (2011) showed that there is a clear difference in the integrity of the pit membrane depending on the ITE's function. While homogenously porous pit membranes are present in conductive ITEs, pit membranes are often perforated in non-conductive ITEs (Figure 1D).
However, it is not clear at what stage of their development the membranes of non-conductive ITEs become perforated, or what mechanisms are responsible. Taken together, these observations suggest that the hydrolytic machinery involved in the development of intervessel pit membranes must have been painstakingly fine-tuned over the course of evolution in order to produce the relatively efficient and safe vessel-based xylem of extant eudicots.

For the same reason, it seems unlikely that such an extensive and complex hydrolytic process is always flawless. One can easily imagine that a local excess of hydrolytic activity or a slight irregularity in the thickness or arrangement of the primary cell wall could give rise to a particularly large pore within the pit membrane (Figures 1A,C). This idea is consistent with the "rare pit” hypothesis (Hargrave et al., 1994; Choat et al., 2003; Wheeler 
et al., 2005; Christman et al., 2009). According to this hypothesis, a small portion of pits contain a large pore, while the vast majority of pits have much narrower, air-tight pores. Exceptionally large pores are occasionally observed with SEM (Figures 1A,C; Sano, 2005) independent of the average membrane porosity; however, it remains uncertain whether these pores are real, or artifacts resulting from sample preparation. The existence of rare leaky pits has been nevertheless supported by particle perfusion experiments (Choat et al., 2003), air-seeding experiments (Christman et al., 2009, 2012), and observed correlations between intervessel pit area and vulnerability to cavitation (Wheeler et al., 2005; Hacke et al., 2006).

The deposition of secondary material resulting in the development of a torus represents a characteristic step in the ontogeny of pits in gymnosperms. The secondary layer is initially deposited over the entire surface of the pit membrane, with its thickness being greatest in the center of the membrane. Subsequently, some of the material is removed by autolysis, which exposes the highly porous margo and defines the final shape and thickness of the torus (Dute, 1994; Dute et al., 2008). Tori are usually depicted as round symmetrical discs. However, tori of many pits show structural irregularities such as scalloped tori and torus extensions (Figures 1E,F). Tori with scalloped margins are characteristic of Cedrus but can occasionally be found in other Pinaceae and Cupressaceae (Richter et al., 2004). Torus extensions are relatively common among gymnosperms, although their occurrence is not frequently highlighted. It is imaginable that these irregularities can potentially prevent tori from properly sealing the apertures. In support of this hypothesis, Schoonmaker et al. (2010) found a higher occurrence of torus extensions in more vulnerable xylem of Picea mariana grown in an understory in comparison with less vulnerable trees grown in an open field. In contrast, Pittermann et al. (2010) found that torus extensions were more frequent in cavitation resistant species of Cupressaceae.

Punctured tori (Figure 1G) represent another irregularity in the structure of gymnosperm pits that appears to be associated with increased vulnerability (Jansen et al., 2012). Punctured tori frequently occur in Pinaceae but are also observed in some members of Cupressaceae and Cephalotaxaceae (Jansen et al., 2012). These "imperfections" likely arise from the combination of plasmodemata present during early developmental stages of the torus, and the lack of matrix removal from the torus (as observed for instance in Abies firma, but not in Metasequoia glyptostroboides, Dute et al., 2008).

In summary, the ontogeny of pits in both angiosperms and gymnosperms is a complex process and the mechanisms regulating this process are not well understood. Obtaining more detailed knowledge of the hydrolytic machinery involved in the remodeling of pit membranes would be particularly useful as rare large pores, irregularities of torus margins, and punctured tori could be underpinned by variation in the hydrolytic activity exerted during the pit membrane development.

\section{DAMAGE TO PIT MEMBRANES BY PHYSICAL AND CHEMICAL AGENTS}

With a typical thickness between 100 and $300 \mathrm{~nm}$, pit membranes represent delicate structures likely prone to structural damage by physical or chemical stress, or a combination of the two. Extensive disruption of pit membranes has been documented with SEM in several studies. Harvey and van den Driessche (1997) observed a higher occurrence of ripped and torn membranes in drought susceptible poplar clones. Sperry et al. (1991) showed that pit membrane degradation and increased vulnerability to cavitation are concomitants of wood senescence in trembling aspen. More recently, pit deterioration has also been documented in grapevine stems infested with the bacterial pathogen Xylella fastidiosa (Sun et al., 2011). While these studies portray extreme situations, they illustrate what may commonly occur in planta, although to a more moderate extent. Choat et al. (2003) highlighted some of these studies and suggested that occasional damage to pit membranes could represent an important source of air-seeding sites. Here we elaborate upon this hypothesis and review possible mechanism potentially causing pit membrane damage.

Under field conditions, substantial mechanical forces can be generated by factors such as wind, snow-load, hail, or rough handling by animals; e.g., large mammalian herbivores bending a twig while chewing on leaves (Cannell and Morgan, 1989; Lucas et al., 2000; Rudnicki et al., 2001). Wood typically exhibits sufficient mechanical strength not to break under these types of loading. However, it is possible that the perturbations are sufficient to deform the pit fields and cause occasional damage to the pit membranes, especially in younger branches. Close correlations between xylem vulnerability and wood density or conduit wall thickness are frequently observed (e.g., Hacke et al., 2001a; Fichot et al., 2010; Plavcová and Hacke, 2012; Lens et al., 2013). It is possible that stronger mechanical reinforcement helps to prevent pit membrane damage caused by external mechanical stress.

Alternatively, this reinforcement may be required to avoid conduit collapse caused by negative xylem pressure (Hacke et al., 2001a; Jacobsen et al., 2005). The implosion of xylem conduits has not been frequently observed except in xylem with a severely perturbed deposition of cell wall lignin (Barnett, 1977; Turner and Somerville, 1997; Coleman et al., 2008; Voelker et al., 2011), suggesting that air-seeding typically occurs before the xylem pressure reaches the implosion limit. This raises yet another important question, namely, what is the effect of the pressure difference exerted on the pit membranes during and shortly before air-seeding. When subjected to internal mechanical stress, pit membranes deflect, and stretch. This may cause transient or permanent changes in pit membrane porosity (Choat et al., 2004) and eventually lead to membrane rupture (Sperry and Hacke, 2004; Domec etal., 2006). There is also evidence that xylem becomes more vulnerable as a result of a previous cavitation event. This "cavitation fatigue" phenomenon has been observed in two poplar species (Populus tremuloides and P. angustifolia), sunflower (Helianthus annuus), and chestnut petioles (Aesculus hippocastanum; Hacke et al., 2001b; Stiller and Sperry, 2002; Anderegg et al., 2013). It was hypothesized that increased air permeability in weakened xylem results from rupture or loosening of pit membrane fibrils (Hacke et al., 2001b), but direct evidence for this idea is still lacking.

In spite of the general perception that pit membranes are fragile, no permanent differences in the permeability of pit membranes to colloidal gold were observed after applying injection pressures 
of up to $6 \mathrm{MPa}$ (Choat et al., 2004). Furthermore, Michaletz et al. (2012) demonstrated that pit membranes of Populus balsamifera are durable under conditions of extreme heat. Exposure to a temperature of $65^{\circ} \mathrm{C}$ did not change pit membrane permeability to air, despite causing severe deformations of conduit walls. However, this result originates from a laboratory experiment and it is possible that additional perturbations can cause pit membrane damage more easily in xylem weakened by the heat. Such situation may readily occur in the field; e.g., as a forest stand is exposed to more wind following forest fire.

Furthermore, the integrity of pit membranes can be disrupted by chemical agents reacting with the structural components of the membrane. Besides water, xylem sap contains a wide array of chemicals, some of which are known to induce the loosening of plant cell walls. Among these are numerous polysaccharide-hydrolyzing enzymes. The destructive effect of cellulase on pit membranes has been demonstrated by a marked increase in xylem hydraulic conductivity following the hydrolytic treatment (Schulte etal., 1987). Under natural conditions, pit membranes weakened by a hydrolytic reaction may serve as gateway for pathogens colonizing the xylem. While some viruses such as the tobacco rattle virus can spread through pit membranes without the need to widen the pores (Garbaczewska et al., 2012), larger bacteria must perturb the structure of the pit membranes in order to penetrate the adjacent conduit (Pérez-Donoso et al., 2010). For instance, Xyllela fastidiousa, which causes the Pierce's disease in grapevine, likely disrupts pit membranes by secreting a cocktail of hydrolytic enzymes including $\beta$-1,4-endoglucanses, xylanases, xylosidases, and polygalacturonases (Roper et al., 2007; Pérez-Donoso et al., 2010). Another bacterium, Pseudomonas fluorescens, has been shown to degrade torus-margo pits in pine wood chips. While the margo region underwent substantial degradation, the torus region remained largely intact, demonstrating the differential resistance of these pit membrane regions to microbial degradation (Burnes et al., 2000). Fungal infestations are also known to cause pit membrane degradation, with most observations being done on dead decaying wood (Schwarze et al., 2006). There is a plethora of fungal pathogens infecting the sapwood of standing trees (e.g., blue stain fungi, root- and trunk-rots); however, little is known about their actual effects on xylem hydraulics.

Another way to alter the pore size in pit membranes is the depletion of $\mathrm{Ca}^{2+}$. Calcium-pectin complexes are presumably present throughout the entire surface of the pit membrane (Zwieniecki et al., 2001; Gortan et al., 2011) or at least in a restricted part of the membrane (Plavcová and Hacke, 2011). Indirect evidence that calcium removal causes enlargement of pit membrane pores has been provided by Sperry and Tyree (1988) and by Herbette and Cochard (2010) who showed that the perfusion of xylem with calcium-chelating agents such as oxalic acid, EGTA, and phosphate buffer results in increased vulnerability to cavitation. In a similar experiment, the stems of Drymis winteri were treated with a calcium-chelating phosphate buffer, which resulted in an increase in the mean pit membrane porosity from 6 to $120 \mathrm{~nm}$ as measured with SEM (Klepsch et al., unpublished). Furthermore, it has been suggested that the rice yellow mottle virus extracts $\mathrm{Ca}^{2+}$ from the pit membrane and incorporates it in its own structures. The result is a loosening of pectin hydrogels and widening of pit membrane pores, in turn allowing systemic virus transport via xylem conduits (Opalka et al., 1998).

Reactive oxygen species (ROS) represent another type of chemical agent potentially capable of disrupting pit membranes, although this hypothesis has not yet been tested. ROS are commonly found in xylem sap and their concentration increases as a result of biotic or abiotic stress (Wang et al., 2008). The oxidative activity of ROS is known to induce cleavage of cell wall polysaccharides in vivo during normal plant growth and development (Schopfer, 2001; Müller et al., 2009). Moreover, high concentrations of ROS may lead to severe oxidative damage. For instance, in two pea (Pisum sativum) cultivars subjected to saline stress, necrotic leaf lesions were induced in close proximity of minor veins and could be linked with the elevated ROS concentration in the leaf apoplast (Hernández et al., 2001).

Thus, more research is still needed to demonstrate whether mature pit membranes stay intact throughout the entire functional period, or whether more or less significant signs of pit damage are encountered. As discussed in the previous text, there is substantial evidence that pit membrane damage occurs; however, it is not yet clear how common this phenomenon is. It is possible that damage accumulates slowly over time, but because old wood is gradually replaced by newly formed wood, vulnerability of the bulk xylem remains constant. However, under some circumstances the accumulation of damage can be so rapid that it overwhelms the capacity for xylem tissue maintenance and renewal. This brings up an interesting question: is there any coordination between the sapwood longevity, pit characteristics and intensity of external and internal stress typically encountered?

Importantly, the mechanisms potentially causing pit damage may not be mutually exclusive. On the contrary, they likely work in tandem and reinforce one another. For instance, the deforming effects of large pressure differences exerted on pit membranes may be amplified by oxidative damage caused by rising ROS concentration in xylem sap during drought. From a broader ecological perspective, pit membrane damage can provide interesting connections between abiotic and biotic stress. For instance, damage to pit membranes by pathogens may render plants more susceptible to drought. This may add another link to what already is an intricate network of feedbacks linking drought stress and pathogen outbreaks (McDowell et al., 2008; Jactel et al., 2012).

\section{CONCLUSIONS}

There is a natural tendency to report the most "perfect looking" specimens of pits in the scientific literature. However, neglecting inherent variability in pit structure may lead to a biased view. Considering the potential importance of the rare pit hypothesis, we suggest that more attention should be given to structural irregularities, as those may represent the rare sites ultimately responsible for air-seeding.

Studying pit irregularities with SEM is challenging, and comparable to the proverbial needle in a haystack problem. Moreover, artifacts potentially associated with sample preparation represent an additional difficulty (Jansen et al., 2008). Thus, studies combining microscopic observations with hydraulic measurements (e.g., air-seeding experiments) will be necessary to move the field 
forward. Gaining a better understanding of the processes that lead to such irregularities provides an additional strategy for addressing this issue. We wish to emphasize that intrinsic developmental flaws and damage caused to the pit membranes by physical or chemical stress may represent two potential sources of irregularities in pit structure.

\section{ACKNOWLEDGMENT}

We thank the editors for the invitation to contribute to this special issue. We are also grateful to Stephanie Stuart and Brendan Choat for discussion and comments on an earlier version of the manuscript. Lenka Plavcová gratefully acknowledges financial support of the Alexander von Humboldt Foundation.

\section{REFERENCES}

Anderegg, W. R. L., Plavcová, L., Anderegg, L. D. L., Hacke, U. G., Berry, J. A., and Field, C. B. (2013). Drought's legacy: multiyear hydraulic deterioration underlies widespread aspen forest die-off and portends increased future risk. Glob. Chang. Biol. 19, 1188-1196. doi: 10.1111/gcb.12100

Barnett, J. (1977). Rings of collapsed cells in Pinus radiata stemwood from lysimetergrown trees subjected to drought. N. Z. J. For. Sci. 6, 461-465.

Benayoun, J., Catesson, A., and Czaninski, Y. (1981). A cytochemical study of differentiation and breakdown of vessel end walls. Ann. Bot. 47, 687-698.

Burnes, T. A., Blanchette, R. A., and Farrell, R. L. (2000). Bacterial biodegradation of extractives and patterns of bordered pit membrane attack in pine wood. Appl. Environ. Microbiol. 66, 5201-5205. doi: 10.1128/AEM.66.12.5201-5205.2000

Butterfield, B., and Meylan, B. (1982). "Cell wall hydrolysis in the tracheary elements of the secondary xylem," in New Perspectives in Wood Anatomy, ed. P. Baas, (Dordrecht: Springer Science+Business Media B. V.), 71-84. doi: 10.1007/978-94-017-2418-0_4

Cannell, M., and Morgan, J. (1989). Branch breakage under snow and ice loads. Tree Physiol. 5, 307-317. doi: 10.1093/treephys/5.3.307

Carlquist, S. (1992). Pit membrane remnants in perforation plates of primitive dicotyledons and their significance. Am. J. Bot. 79, 660-672. doi: 10.2307/2444882

Carlquist, S., and Schneider, E. (1997). SEM studies on vessels in ferns. 2. Pteridium. Am. J. Bot. 84, 581-581. doi: 10.2307/2445893

Carlquist, S., and Schneider, E. L. (2001). Vessels in ferns: structural, ecological, and evolutionary significance. Am. J. Bot. 88, 1-13. doi: 10.2307/2657121

Chaffey, N., Barnett, J., and Barlow, P. (1997). Cortical microtubule involvement in bordered pit formation in secondary xylem vessel elements of Aesculus hippocastanum L. (Hippocastanaceae): a correlative study using electron microscopy and indirect immunofluorescence microscopy. Protoplasma 197, 64-75. doi: 10.1007/BF01279885

Choat, B., Ball, M., Luly, J., and Holtum, J. (2003). Pit membrane porosity and water stress-induced cavitation in four co-existing dry rainforest tree species. Plant Physiol. 131, 41-48. doi: 10.1104/pp.014100

Choat, B., Jansen, S., Zwieniecki, M. A., Smets, E., and Holbrook, N. M. (2004). Changes in pit membrane porosity due to deflection and stretching: the role of vestured pits. J. Exp. Bot.55, 1569-1575. doi: 10.1093/jxb/erh173

Choat, B., Cobb, A. R., and Jansen, S. (2008). Structure and function of bordered pits: new discoveries and impacts on whole-plant hydraulic function. New Phytol. 177, 608-626. doi: 10.1111/j.1469-8137.2007.02317.x

Christman, M. A., Sperry, J. S., and Adler, F. R. (2009). Testing the "rare pit" hypothesis for xylem cavitation resistance in three species of Acer. New Phytol. 182, 664-674. doi: 10.1111/j.1469-8137.2009.02776.x

Christman, M. A., Sperry, J. S., and Smith, D. D. (2012). Rare pits, large vessels and extreme vulnerability to cavitation in a ring-porous tree species. New Phytol. 193, 713-720. doi: 10.1111/j.1469-8137.2011.03984.x

Coleman, H. D., Samuels, A. L., Guy, R. D., and Mansfield, S. D. (2008). Perturbed lignification impacts tree growth in hybrid poplar - a function of sink strength, vascular integrity, and photosynthetic assimilation. Plant Physiol. 148, 1229-1237. doi: 10.1104/pp.108.125500

Czaninski, I. (1972). Observations ultrastructurales sur l'hydrolyse des parois primaires des vaisseaux chez le Robinia pseudo-acacia L. et l'Acer pseudoplatanus L. C. R. Acad. Sci. (Paris) 275, 361-363.
Domec, J.-C., Lachenbruch, B., and Meinzer, F. C. (2006). Bordered pit structure and function determine spatial patterns of air-seeding thresholds in xylem of Douglas-fir (Pseudotsuga menziesii; Pinaceae) trees. Am. J. Bot. 93, 1588-1600. doi: 10.3732/ajb.93.11.1588

Domec, J.-C., Lachenbruch, B., Meinzer, F. C., Woodruff, D. R., Warren, J. M., and McCulloh, K. A. (2008). Maximum height in a conifer is associated with conflicting requirements for xylem design. Proc. Natl. Acad. Sci. USA 105, 1206912074. doi: 10.1073/pnas.0710418105

Dute, R. (1994). Pit membrane structure and development in Ginkgo biloba. IAWA J. 15, 75-90.

Dute, R., Hagler, L., and Black, A. (2008). Comparative development of intertracheary pit membranes in Abies firma and Metasequoia glyptostroboides. IAWA J. 29, 277-289. doi: 10.1163/22941932-90000186

Fichot, R., Barigah, T. S., Chamaillard, S., Le Thiec, D., Laurans, F., Cochard, H., etal., (2010). Common trade-offs between xylem resistance to cavitation and other physiological traits do not hold among unrelated Populus deltoides $\times$ Populus nigra hybrids. Plant Cell Environ. 33, 1553-1568. doi: 10.1111/j.1365-3040.2010.02164.x

Garbaczewska, G., Otulak, K., Chouda, M., and Chrzanowska, M. (2012). Ultrastructural studies of plasmodesmatal and vascular translocation of tobacco rattle virus (TRV) in tobacco and potato. Acta Physiol. Plant. 34, 1229-1238. doi: 10.1007/s11738-012-0960-8

Gortan, E., Nardini, A., Salleo, S., and Jansen, S. (2011). Pit membrane chemistry influences the magnitude of ion-mediated enhancement of xylem hydraulic conductance in four Lauraceae species. Tree Physiol. 31, 48-58. doi: 10.1093/treephys/tpq101

Hacke, U. G., Sperry, J. S., Pockman, W. T., Davis, S. D., and McCulloh, K. A. (2001a). Trends in wood density and structure are linked to prevention of xylem implosion by negative pressure. Oecologia 126, 457-461. doi: 10.1007/s004420 100628

Hacke, U. G., Stiller, V., Sperry, J. S., Pittermann, J., and McCulloh, K. A. (2001b). Cavitation fatigue. Embolism and refilling cycles can weaken the cavitation resistance of xylem. Plant Physiol. 125, 779-786. doi: 10.1104/pp.125. 2.779

Hacke, U. G., Sperry, J. S., Wheeler, J. K., and Castro, L. (2006). Scaling of angiosperm xylem structure with safety and efficiency. Tree Physiol. 26, 689-701. doi: 10.1093/treephys/26.6.689

Hacke, U., Sperry, J., Feild, T., Sano, Y., Sikkema, E., and Pittermann, J. (2007). Water transport in vesselless angiosperms: conducting efficiency and cavitation safety. Int. J. Plant Sci. 168, 1113-1126. doi: 10.1086/520724

Hacke, U. G., and Jansen, S. (2009). Embolism resistance of three boreal conifer species varies with pit structure. New Phytol. 182, 675-686. doi: 10.1111/j.14698137.2009.02783.x

Hargrave, K., Kolb, K., Ewers, F., and Davis, S. (1994). Conduit diameter and drought-induced embolism in Salvia mellifera Greene (Labiatae). New Phytol. 126, 695-705. doi: 10.1111/j.1469-8137.1994.tb02964.x

Harvey, H., and van den Driessche, R. (1997). Nutrition, xylem cavitation and drought resistance in hybrid poplar. Tree Physiol. 17, 647-654. doi: 10.1093/treephys/17.10.647

Herbette, S., and Cochard, H. (2010). Calcium is a major determinant of xylem vulnerability to cavitation. Plant Physiol. 153, 1932-1939. doi: 10.1104/pp.110.155200

Hernández, J. A., Ferrer, M. A., Jiménez, A., Barceló, A. R., and Sevilla, F. (2001). Antioxidant systems and $\mathrm{O} 2 .-/ \mathrm{H} 2 \mathrm{O} 2$ production in the apoplast of pea leaves. Its relation with salt-induced necrotic lesions in minor veins. Plant Physiol. 127, 817-831. doi: 10.1104/pp.010188

Imamura, Y., and Harada, H. (1973). Electron microscopic study on the development of the bordered pit in coniferous tracheids. Wood Sci. Technol. 7, 189-205. doi: 10.1007/BF00355549

Jacobsen, A. L., Ewers, F. W., Pratt, R. B., Paddock, III, A., and Davis, S. D. (2005). Do xylem fibers affect vessel cavitation resistance? Plant Physiol. 139, 546-556. doi: 10.1104/pp.104.058404

Jactel, H., Petit, J., Desprez-Loustau, M.-L., Delzon, S., Piou, D., Battisti, A., et al., (2012). Drought effects on damage by forest insects and pathogens: a metaanalysis. Glob. Chang. Biol. 18, 267-276. doi: 10.1111/j.1365-2486.2011.02512.x

Jansen, S., Pletsers, A., and Sano, Y. (2008). The effect of preparation techniques on SEM-imaging of pit membranes. IAWA J. 29, 161-178. doi: 10.1163/2294193290000177 
Jansen, S., Choat, B., and Pletsers, A. (2009). Morphological variation of intervessel pit membranes and implications to xylem function in angiosperms. Am. J. Bot. 96, 409-419. doi: 10.3732/ajb.0800248

Jansen, S., Lamy, J.-B., Burlett, R., Cochard, H., Gasson, P., and Delzon, S. (2012). Plasmodesmatal pores in the torus of bordered pit membranes affect cavitation resistance of conifer xylem. Plant Cell Environ. 35, 1109-1120. doi: 10.1111/j.1365-3040.2011.02476.x

Kim, J. S., Awano, T., Yoshinaga, A., and Takabe, K. (2011). Temporal and spatial diversities of the immunolabeling of mannan and xylan polysaccharides in differentiating earlywood ray cells and pits of Cryptomeria japonica. Planta 233, 109-122. doi: 10.1007/s00425-010-1283-x

Lens, F., Tixier, A., Cochard, H., Sperry, J. S., Jansen, S., and Herbette, S. (2013) Embolism resistance as a key mechanism to understand adaptive plant strategies. Curr. Opin. Plant Biol. 16, 287-292. doi: 10.1016/j.pbi.2013.02.005

Lucas, P. W., Turner, I. M., Dominy, N. J., and Yamashita, N. (2000). Mechanical defences to herbivory. Ann. Bot. 86, 913-920. doi: 10.1006/anbo.2000.1261

McDowell, N., Pockman, W. T., Allen, C. D., Breshears, D. D., Cobb, N., Kolb, T., et al., (2008). Mechanisms of plant survival and mortality during drought: why do some plants survive while others succumb to drought? New Phytol. 178, 719-739. doi: 10.1111/j.1469-8137.2008.02436.x

Michaletz, S. T., Johnson, E., and Tyree, M. (2012). Moving beyond the cambium necrosis hypothesis of post-fire tree mortality: cavitation and deformation of xylem in forest fires. New Phytol. 194, 254-263. doi: 10.1111/j.14698137.2011.04021.x

Müller, K., Linkies, A., Vreeburg, R. A., Fry, S. C., Krieger-Liszkay, A., and LeubnerMetzger, G. (2009). In vivo cell wall loosening by hydroxyl radicals during cress seed germination and elongation growth. Plant Physiol. 150, 1855-1865. doi 10.1104/pp.109.139204

O'Brien, T., and Thimann, K. (1967). Observations on the fine structure of the oat coleoptile. Protoplasma 63, 385-416. doi: 10.1007/BF01252947

Opalka, N., Brugidou, C., Bonneau, C., Nicole, M., Beachy, R. N., Yeager, M., et al., (1998). Movement of rice yellow mottle virus between xylem cells through pit membranes. Proc. Natl. Acad. Sci. USA 95, 3323-3328. doi: 10.1073/pnas.95.6.3323

Pérez-Donoso, A. G., Sun, Q., Roper, M. C., Greve, L. C., Kirkpatrick, B., and Labavitch, J. M. (2010). Cell wall-degrading enzymes enlarge the pore size of intervessel pit membranes in healthy and Xylella fastidiosa-infected grapevines. Plant Physiol. 152, 1748-1759. doi: 10.1104/pp.109.148791

Pittermann, J., Choat, B., Jansen, S., Stuart, S. A., Lynn, L., and Dawson, T. E. (2010). The relationships between xylem safety and hydraulic efficiency in the Cupressaceae: the evolution of pit membrane form and function. Plant Physiol. 153, 1919-1931. doi: 10.1104/pp.110.158824

Plavcová, L., and Hacke, U. G. (2011). Heterogeneous distribution of pectin epitopes and calcium in different pit types of four angiosperm species. New Phytol. 192 885-897. doi: 10.1111/j.1469-8137.2011.03842.x

Plavcová, L., Hacke, U. G., and Sperry, J. S. (2011). Linking irradiance-induced changes in pit membrane ultrastructure with xylem vulnerability to cavitation. Plant Cell Environ. 34, 501-513. doi: 10.1111/j.1365-3040.2010.02258.x

Plavcová, L., and Hacke, U. G. (2012). Phenotypic and developmental plasticity of xylem in hybrid poplar saplings subjected to experimental drought, nitrogen fertilization, and shading. J. Exp. Bot. 63, 6481-6491. doi: 10.1093/jxb/ers303

Richter, H. G., Grosser, D., Heinz, I., and Gasson, P. (2004). IAWA list of microscopic features for softwood identification. IAWA J. 25, 1-70. doi: 10.1163/2294193290000349

Roper, M. C., Greve, L. C., Warren, J. G., Labavitch, J. M., and Kirkpatrick, B. C. (2007). Xylella fastidiosa requires polygalacturonase for colonization and pathogenicity in Vitis vinifera grapevines. Mol. Plant Microbe Interact. 20, 411-419. doi: 10.1094/MPMI-20-4-0411

Rudnicki, M., Silins, U., Lieffers, V. J., and Josi, G. (2001). Measure of simultaneous tree sways and estimation of crown interactions among a group of trees. Trees 15 83-90. doi: 10.1007/s004680000080

Sano, Y. (2005). Inter- and intraspecific structural variation among intervascular pit membranes, as revealed by field-emission scanning electron microscopy. Am. J. Bot. 92, 1077-1084. doi: 10.3732/ajb.92.7.1077

Sano, Y., Morris, H., Shimada, H., De Craene, L. P. R., and Jansen, S. (2011). Anatomical features associated with water transport in imperforate tracheary elements of vessel-bearing angiosperms. Ann. Bot. 107, 953-964. doi: 10.1093/aob/ mcr042
Schoonmaker, A. L., Hacke, U. G., Landhäusser, S. M., Lieffers, V. J., and Tyree, M. T. (2010). Hydraulic acclimation to shading in boreal conifers of varying shade tolerance. Plant Cell Environ. 33, 382-393. doi: 10.1111/j.1365-3040.2009. 02088.x

Schopfer, P. (2001). Hydroxyl radical-induced cell-wall loosening in vitro and in vivo: implications for the control of elongation growth. Plant J. 28, 679-688. doi: 10.1046/j.1365-313x.2001.01187.x

Schulte, P. J., Gibson, A. C., and Nobel, P. S. (1987). Xylem anatomy and hydraulic conductance of Psilotum nudum. Am. J. Bot. 74, 1438-1445. doi: 10.2307/ 2444320

Schwarze, F. W., Landmesser, H., Zgraggen, B., and Heeb, M. (2006). Permeability changes in heartwood of Picea abies and Abies alba induced by incubation with Physisporinus vitreus. Holzforschung 60, 450-454. doi: 10.1515/HF. 2006.071

Sperry, J. S., and Tyree, M. T. (1988). Mechanism of water stress-induced xylem embolism. Plant Physiol. 88, 581-587. doi: 10.1104/pp.88.3.581

Sperry, J., Perry, A., and Sullivan, J. (1991). Pit membrane degradation and airembolism formation in ageing xylem vessels of Populus tremuloides Michx. J. Exp. Bot. 42, 1399-1406. doi: 10.1093/jxb/42.11.1399

Sperry, J. S., and Hacke, U. G. (2004). Analysis of circular bordered pit function I. Angiosperm vessels with homogenous pit membranes. Am. J. Bot. 91, 369-385. doi: 10.3732/ajb.91.3.369

Sperry, J., Hacke, U., Feild, T., Sano, Y., and Sikkema, E. (2007). Hydraulic consequences of vessel evolution in angiosperms. Int. J. Plant Sci. 168, 1127-1139. doi: $10.1086 / 520726$

Stiller, V., and Sperry, J. S. (2002). Cavitation fatigue and its reversal in sunflower (Helianthus annuus L.). J. Exp. Bot. 53, 1155-1161. doi: 10.1093/jexbot/53.371.1155

Sun, Q., Greve, L. C., and Labavitch, J. M. (2011). Polysaccharide compositions of intervessel pit membranes contribute to Pierce's disease resistance of grapevines. Plant Physiol. 155, 1976-1987. doi: 10.1104/pp.110.168807

Turner, S. R., and Somerville, C. R. (1997). Collapsed xylem phenotype of Arabidopsis identifies mutants deficient in cellulose deposition in the secondary cell wall. Plant Cell 9, 689-701. doi: 10.1105/tpc.9.5.689

Voelker, S. L., Lachenbruch, B., Meinzer, F. C., Kitin, P., and Strauss, S. H. (2011). Transgenic poplars with reduced lignin show impaired xylem conductivity, growth efficiency and survival. Plant Cell Environ. 34, 655-668. doi: 10.1111/j.1365-3040.2010.02270.x

Wang, R., Chen, S., Zhou, X., Shen, X., Deng, L., Zhu, H., et al. (2008). Ionic homeostasis and reactive oxygen species control in leaves and xylem sap of two poplars subjected to $\mathrm{NaCl}$ stress. Tree Physiol. 28, 947-957. doi: 10.1093/treephys/28.6.947 Wardrop, A. (1954). The mechanism of surface growth involved in the differentiation of fibres and tracheids. Aust. J. Bot. 2, 165-175. doi: 10.1071/ BT9540165

Wheeler, J. K., Sperry, J. S., Hacke, U. G., and Hoang, N. (2005). Inter-vessel pitting and cavitation in woody Rosaceae and other vesselled plants: a basis for a safety versus efficiency trade-off in xylem transport. Plant Cell Environ. 28, 800-812. doi: 10.1111/j.1365-3040.2005.01330.x

Zwieniecki, M. A., Melcher, P. J., and Holbrook, N. M. (2001). Hydrogel control of xylem hydraulic resistance in plants. Science 291, 1059-1062. doi: $10.1126 /$ science. 1057175

Conflict of Interest Statement: The authors declare that the research was conducted in the absence of any commercial or financial relationships that could be construed as a potential conflict of interest.

Received: 29 August 2013; paper pending published: 07 October 2013; accepted: 22 October 2013; published online: 12 November 2013.

Citation: Plavcová L, Jansen S, Klepsch M and Hacke UG (2013) Nobody's perfect: can irregularities in pit structure influence vulnerability to cavitation? Front. Plant Sci. 4:453. doi: 10.3389/fpls.2013.00453

This article was submitted to Plant Physiology, a section of the journal Frontiers in Plant Science.

Copyright (C) 2013 Plavcová, Jansen, Klepsch and Hacke. This is an open-access article distributed under the terms of the Creative Commons Attribution License (CC BY). The use, distribution or reproduction in other forums is permitted, provided the original author(s) or licensor are credited and that the original publication in this journal is cited, in accordance with accepted academic practice. No use, distribution or reproduction is permitted which does not comply with these terms. 